\title{
Positive Psychologists on Positive Psychology: Denise Quinlan
}

\author{
Interview by \\ Aaron Jarden
}

\begin{abstract}
Denise Quinlan is a graduate of the University of Pennsylvania's Masters in Applied Positive Psychology (MAPP) program. She is currently completing a PhD in Psychology at the University of Otago in New Zealand on group strengths interventions with children.
\end{abstract}

\section{In general terms and in your mind, what are some of the distinctive features of positive psychology?}

It's the focus on understanding what enables and supports wellbeing and how we can enhance it. Within positive psychology there are many different areas of research examining how that occurs, but we don't yet have an integrated understanding of wellbeing, for example understanding the relationship between hedonics and eudaimonics, and how happiness unfolds across time and within the person.

\section{What would you say are some of the goals of positive psychology?}

To better understand and support people to experience mental health and wellbeing, at an individual level in therapeutic settings and individual coaching settings, and at the group level, in schools, workplaces, and right up to the societal level, where we can think about flourishing as a societal good. One of the challenges that positive psychology can perhaps address is that of wellbeing being regarded as an individual benefit and not the purview of government. If positive psychology can demonstrate that wellbeing has societal benefits, if it is seen as a public good, then supporting wellbeing at a societal level becomes part of the political agenda.

\section{What are some of the big challenges that positive psychology currently faces?}

The one that jumps to mind is research catching up with the practice. People are keen to implement research, and are sometimes basing that on one or two pieces of research which perhaps aren't even with their population, and that's the best they have got to go with. A better understanding of the mechanisms through which interventions work will enable us to design more effective and appropriate interventions for different populations. There is a growing awareness of the importance of context among researchers and that's good; but I don't know if consumers of the research are as aware. We expect a lot of people to be very sophisticated consumers of research, and that's one of the challenges of positive psychology. I have been concerned about the use of strengths interventions as if they are a fool-proof way to enhance wellbeing. Strengths are not a wind-up toy, ready to be taken out of the box, and off you go. Creating a shared language of strengths, understanding different definitions and how strengths

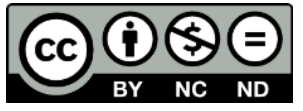

Copyright belongs to the author(s) www.internationaljournalofwellbeing.org 
are valued differently by different groups and in different contexts is important when using a strengths approach. Another big challenge is really understanding what wellbeing is, how it occurs and unfolds with different individuals and groups. Hedonic and eudaimonic theory have both provided valuable insights into human behaviour, but are often studied separately by different people, but both actually occur in a single human being, in a given context. Every individual enjoys moments of hedonic and eudaimonic wellbeing. By focusing on them separately we perhaps miss the interplay and balance between them that supports wellbeing. I don't think it's always possible to parse wellbeing into constituent elements; are my hoots of laughter with my family at the end of a challenging ski run pure pleasure at the run or meaning and fulfilment at being loved and part of a family, or a sense of being aligned with my purpose of being a good mother? I do know that if I tried to look at it, I would kill the moment, and if I did it out loud, my kids would probably kill me.

Were there any key events that made you move into the area of positive psychology? I mean, how did you get into the field of positive psychology?

I had read Learned Optimism and Authentic Happiness by Marty Seligman and was using some of that work in workshops I was running. I had a business called 'What To Do Next', which delivered three-day seminars for people who were trying to work out where they were going to go next with their lives. The seminar used a lot of different tools, some of which came from positive psychology. I saw an advert for the Masters of Applied Positive Psychology (MAPP) programme and I thought, 'that would be interesting, but impossible from NZ'. I applied and my very loving husband said we'd manage the fees and travel costs. He has pointed out to me that I could have had a diamond ring, a sports car and some change. Luckily, we share an interest in wellbeing so he thought it was worthwhile.

\section{So that's the Masters of Applied Positive Psychology programme in Philadelphia? Can you tell us a bit more about that?}

The programme is run on an executive study model with three days a month onsite, and study and assignments in between. Each on site was three days of lectures from some of the leading people in the field. To sit in a lecture theatre and have someone share their work and learning with you always feels like a privilege to me, so it was a fantastic time. In between on sites, there were lots of assignments and online meetings; that was a lot of work. But honestly, getting to go to Philadelphia and to listen to people like Barbara Fredrickson, Chris Peterson, Martin Seligman, Sonya Lyubomirsky, George Vaillant and Jonathan Haidt was a joy. David Cooperrider and Isaac Prilletensky both focus on wellbeing at the community or group levelwhere positive psychology has the least research. Their work provided a great opportunity to balance the individual focus of much of positive psychology research. They were also both inspiring individuals to listen to.

\section{So you go to Philadelphia for three days a month, for about 10 trips over a year, and you get access to all these world leaders. What would you say is the overall highlight of the training?}

It's really hard to say! Probably the first immersion week because I got to hear so many people in that week; George Valliant, Barbara Fredrickson, Sonya Lyubomirsky, Martin Seligman, Chris Peterson. It was amazing to be suddenly immersed in an environment where people really cared about wellbeing and were making it their life's work. I had worked in stock broking and management consulting for big firms in the UK and in New Zealand, so I'd often 
been in environments where wellbeing was seen as soft and fuzzy, and not something worthwhile-it was all about 'show me the impact on the bottom line'. So to be in an environment where people were actually all interested in wellbeing, that was really exciting.

\section{Can you tell me a little bit about your work in positive psychology?}

I'm currently a PhD student at the University of Otago studying group strengths interventions with 10-12 year olds. When I had previously worked with adults, participants on my programme often said, 'Why didn't I learn this at school?', and 'Why is no one teaching this to my kids?'. After the MAPP programme I worked with Karen Reivich as a trainer helping deliver positive psychology training to teachers which included strengths, resilience training and information on meaning and purpose. I was interested in wellbeing interventions for schools and finding out whether or not a 'pure' strengths programme without the other components would actually make a difference to wellbeing. Once into the $\mathrm{PhD}$ I became just as interested in questions like, 'What kinds of outcome measures are most appropriate?', 'What are the strategies being used to teach strengths?', 'How can we enhance the effectiveness of strengths interventions?' and 'Why has no one looked at the effect of a strengths intervention on the group?'. I developed a classroom intervention involving teachers and students which focused on recognising strengths in others as well as the self. I delivered the programme to six classrooms over seven weeks. I'm currently analysing the data and hope to finish in the next six months.

\section{Who do you admire in the strengths area?}

The people that jump out to me are some of the teacher practitioners who've taken the research and applied it in very thoughtful and insightful ways with their students. Some of the teachers at Geelong Grammar [Australia] that I've seen working are very inspiring. In terms of the research, Chris Peterson deserves so much credit for creating the VIA. I've been re-reading the introduction to the VIA handbook; his insights into the VIA's potential and its limitations are worth another look. I think he was aware from the start of the potentially different role of strengths in different societies and the role of groups in encouraging strengths or not. Karen Reivich and Jane Gillham have done very good work in developing strengths programs for schools with a balance of creative and engaging exercises and awareness of the importance of relationship and group culture in strengths programs. People like Jenny Fox Eades in the UK, have adapted the VIA for younger students and use it in conjunction with oral story-telling to create a powerful approach. Jenny is very aware of what works for students and teachers so she is a good example of a critical user of positive psychology research.

\section{What would you do differently if you started learning about positive psychology again?}

I'd get much more critical information much earlier on. I'd like to know more about the 'boundary riders'; the people who are not necessarily classified as positive psychologists, but are doing related work. I would have spent more time studying the social psychology side of positive psychology, and emotions research. Overall, I would have liked to have had more exposure to some of the good critiques of positive psychology and to have had a clearer picture of where positive psychology sits in relation to the other branches of psychology. 
What would your advice be to someone starting out who could not afford to do a MAPP programme or similar? What kind of training advice would you give to someone in that situation who wants to learn a lot more about positive psychology?

Harvard and Penn both offer cheaper online programs where you can get a programme similar to the MAPP syllabus. I would say get your hands on some of the good readings in the area. Resources like Chris Peterson's Primer in Positive Psychology. Just read widely.

What's one book to read for someone coming into this area who has not read anything yet?

Jonathan Haidt's The Happiness Hypothesis is one I really enjoyed reading. I don't know if it's a good first book, but I really like the ideas in it. Chris Peterson's Primer in Positive Psychology is a good broad starting point. Kate Hefferson's and Ilona Boniwell's new book Positive Psychology: Theory, Research and Application is also a great starting point.

In your training, you have met a lot of the key people in the field. Who do you look up to in the field?

Jonathan Haidt was a great lecturer at MAPP - I really like his work on hive psychology. I look up to George Variant for his appreciation of humanity, to Barbara Frederickson for her pioneering research, to Karen Reivich and Jane Gillham for the work they have done on the Penn Resilience Programme and Marty Seligman for his breadth of vision. I also respect people like Tayyab Rashid, who integrates his practice as a therapist with good research, and who is quietly innovating within the strengths area. Todd Kashdan is helping invigorate and challenge the field, and I think that's helpful.

\section{Who do you think is helpful in the field?}

Martin Seligman has been very helpful and supportive to me and other MAPP graduates. Everyone within positive psychology who I've e-mailed or spoken to has been helpful. I've learned a lot from working with Karen Reivich who is a great trainer and programme designer. Todd Kashdan has been helpful in discussing ideas and so have Tayyab Rashid and Carmel Proctor from the UK.

\section{Is there an area of positive psychology you still find difficult to understand?}

It will be nice when we are able to join the dots up a little more. It sometimes feels like we're looking at lots of different areas under a microscope at different levels of magnification, so it's hard to know how things map across to each other. Whether we're looking at emotions and emotional responses, at a very micro level, or at long-term social support and wellbeing, getting from 28,000 feet to ground level and back up again is sometimes quite a challenge - to mesh that together. These theories have been described as metaphors, and I think it'd be great if the metaphors knitted up a little more. I really like an article by Ken Sheldon which described six different irreducible levels at which wellbeing occurs, from psychological need satisfaction at the bottom level up to cultural factors at the top. It was good to see a big picture map.

\section{Is there anything you'd like to add or comment on that I have not asked about?}

If I was talking to someone coming into the field of positive psychology, I would say there are lots of really interesting pockets, but don't lose sight of the big picture. My concern is that people jump into a pocket and act like that is the one solution, when the reality is that no one factor explains everything. The area within positive psychology that most excites me is 
relationships because it's pivotal for wellbeing across the life span but so challenging for most people. I think we still underestimate the importance of relationships in many areas of life, including education. Most of the great educators I've met have a sense that teaching is all about connection with the student. I tell teachers that if they have a broadband connection with a student, then they can teach them anything. If they're on dial-up, it's going to be hard. One of the interesting things about strengths for me is how appreciation of another's strengths can be used to build a relationship. I often describe the VIA strengths to teachers as 24 ways to love a difficult child.

\section{Author}

Aaron Jarden

Open Polytechnic of New Zealand

aaron.jarden@openpolytechnic.ac.nz 